\section{REVIEW IN “HEMODYNAMIC RESPONSE AFTER \\ CONCURRENT CROSS EXERCISE IN HYPERTENSIVE WOMEN" FROM WANDERLEY ET AL., 2020}

\author{
REVISÃO SOBRE "RESPOSTAS HEMODINÂMICAS PÓS-EXERCÍCIO CONCORRENTE CRUZADO EM MULHERES \\ HIPERTENSAS" POR WANDERLEY ETAL., 2020

\section{REVISIÓN SOBRE "RESPUESTAS HEMODINÁMICAS POSTEJERCICIO CONCURRENTE CRUZADO EN MUJERES HIPERTENSAS"POR WANDERLEY ETAL., 2020}

\section{Rubens Vinícius Letieri1,3 (ID (Physical Education Professional) Guilherme Eustáquio Furtado² (iD (Physical Education Professional) Bruno Fernandes Antunez' (ID) (Physical Education Professional) Mayrhon José Abrantes Farias' (iD) (Physical Education Professional) \\ 1. Multidisciplinary Research Nucleus in Physical Education (NIMEF), Federal University of Tocantins (UFT), Tocantinópolis, Brazil. \\ 2. Research Unit for Sport and Physical Activity (CIDAF- UID/ PTD/04213/2016), Faculty of Sport Science and Physical Education, University of Coimbra (FCDEF-UC), Coimbra, Portugal. \\ 3. Post doctoral Researcher at the Rehabilitation Sciences Program - Federal University of Alfenas (UNIFAL), Alfenas, Brazil.}

\section{Correspondência:}

Rubens Vinícius Letieri Núcleo de Investigação Multidisciplinar em Educação Física (NIMEF) - Universidade Federal do Tocantins (UFT). Avenida Nossa Senhora de Fátima, 1558 - Centro, Tocantinópolis, TO, Brazil 77900-000.

rubens.letieri@gmail.com

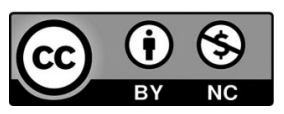

In attention to paper "Hemodynamic response after concurrent cross exercise in hypertensive women" published in RBME, we would respectfully like to make some considerations about the methodological procedures conducted by Wanderley et al.

The methodological proposal of the "cross-concurrent exercise" seems interesting, however we have important notes:

1. how to affirm that the magnitude of the positive effect was due to the "competition" effect between the strength exercise and the aerobic exercise? At this point, it is not possible to affirm this effect, as there was no isolated group of each exercise modality, as pointed out by Wilson et al. ${ }^{1}$ At the beginning of the methodology, the authors refer that 15 women aged 40 to 60 years and who practiced AS and ER for 3 weeks were selected. What would be AS? Why adopt this criterion, considering that 3 weeks are still insufficient to observe a great magnitude of chronic adaptations, especially in strength training?

2. The authors used an 8RM test with a 75\% training load for 10 repetitions. This, in fact, can underestimate the real workload of strength training, certainly the maximum number of repetitions would be above 10 . Adjusted procedures in similar studies are available in the literature, which apply and recommend the 10RM test.,3 Additionally, pointing out the reference of the predictive equation is relevant, as it increases the reliability of the adopted method. It is important to report that the internal validity and reliability of the adopted protocol are fundamental. The magnitude of the change in muscle strength required for real differences to occur after an intervention can be determined by the reliability statistics and, subsequently, sample sizes for future studies can be calculated. Thus, according to Hopkins, 2000, ${ }^{4}$ the following items are important for determining reliability: a) systematic bias; b) variation in the same person and c) test-retest correlation.

3. The control of aerobic training does not seem to have been adequately monitored. The authors affirm the use of Borg's perceived effort scale with 14 points indicated as "intense".

In addition to the original scale not adopting the term "intense", the value of 14 points can be considered as an intermediate factor. Already, the value 15 refers to the term "hard", being closer to the term adopted by the authors. In addition, how can we infer that the intensity indicated refers only to the effects of walking and not to the accumulation of training load from also strength exercises? How to differentiate the stimulus adopted as "aerobic training" from an active rest between the strength series? Would a simple walk be enough stimulus to generate values considered intense by the Borg scale? For the proposal of a new intervention protocol, the authors did not perform a $\mathrm{VO}_{2}$ max test. nor did they indicate a range of effort within these parameters. In addition, heart rate control during aerobic exercise is not indicated. Thus, the aerobic training protocol lacks essential information that points to the effect of competition between variables.

All authors declare no potential conflict of interest related to this article

AUTHORS' CONTRIBUTIONS: RL and GF: Intellectual conception, writing and preparation of whole letter; BA and MF: writing and preparation of whole study. All authors revised and approved the final version of the manuscript.

\section{REFERENCES}

1. Wilson JM, Marin PJ, Rhea MR, Wilson SMC, Loenneke JP, Anderson JC. Concurrent training: A meta-analysis examining interference of aerobic and resistance exercises. J Strength Cond Res. 2012;26(8):2293-307.

2. Stone WJ, Schafer MA, Arnett SW, Lyons TS. Post Exercise Hypotension Following Concurrent Exercise: Does Order of Exercise Modality Matter? Int J Exerc Sci. 2020;13(2):36.
3. Haff GG, Triplett NT. National Strength and Conditioning Association (US) Essentials of strength training and conditioning. 4th ed. Champaign, IL: Human Kinetics; 2016.

4. Hopkins WG. Measures of reliability in sports medicine and science. Vol. 30, Sports Medicine. Adis International Ltd; 2000; 1-5. 